\title{
Carbohydrate mediation of boar sperm binding to oviductal epithelial cells in vitro
}

\author{
C. E. Green ${ }^{1}$, J. Bredl' ${ }^{1}$, W. V. Holt ${ }^{2}$, P. F. Watson ${ }^{1}$ and A. Fazeli ${ }^{2 *}$ \\ ${ }^{1}$ Royal Veterinary College, Royal College Street, London NW1 OTU, UK; and ${ }^{2}$ Institute of \\ Zoology, Regents Park, London NW1 4RY, UK
}

\begin{abstract}
After mating, mammalian spermatozoa are transported to the lower oviductal isthmus. Spermatozoa are sequestered at the isthmus by attaching and interacting with oviductal epithelial cells, hence forming a sperm reservoir. In several mammalian species, specific carbohydrates mediate spermoviductal epithelial cell binding. A quantitative in vitro free cell bioassay was developed to investigate the involvement of carbohydrate recognition in pig spermoviductal epithelial cell interactions. This assay was validated. The sensitivity of the assay was such that it was possible to discriminate between different sperm concentrations and sperm-oviductal epithelial cell co-incubation
\end{abstract}

periods, spermatozoa with damaged plasma membranes and epithelial cells of non-reproductive origin. Optimal conditions were used to incubate spermatozoa and oviductal epithelial cells in the presence of six hexose sugars at concentrations of $0,2,10$ and $50 \mathrm{mmol} \mathrm{I}^{-1}$. A significant $(P \leqslant 0.05)$ reduction in the binding of spermatozoa to the oviductal epithelium was detected with 2, 10 and 50 mmol maltose $\mathrm{I}^{-1}, 50 \mathrm{mmol}^{2}$ lactose $\mathrm{I}^{-1}$ and $50 \mathrm{mmol}^{\mathrm{mannose}} \mathrm{I}^{-1}$. These findings support the hypothesis that attachment of pig spermatozoa to oviductal epithelium before fertilization is mediated by carbohydrate recognition.

\section{Introduction}

After deposition of semen in the female reproductive tract during mating, spermatozoa are transported to the oviduct in mammals (Hunter, 1984; Smith and Yanagimachi, 1991). Spermatozoa are sequestered in the oviduct by attachment to oviductal epithelial cells (Hunter, 1981; Hunter and Nichol, 1983), resulting in the formation of a sperm reservoir. In many species, the sperm reservoir is located primarily in the lower oviductal isthmus (Hunter and Nichol, 1983; Smith and Yanagimachi, 1990). Spermatozoa may reside in the isthmus for several hours (mice), up to a few days (horses) or even months (bats) (Neubaum and Wolfner, 1999) until they are released at the time of ovulation. The isthmic sperm reservoir not only serves as a storage site for the timely co-ordination of fertilization, but also maintains the fertilizing ability of spermatozoa (Neubaum and Wolfner, 1999; Gualtieri and Talevi, 2000). Attachment of spermatozoa to the oviductal mucosa in vivo (Suarez, 1987), and to oviductal epithelial cell monolayers (Thomas and Ball, 1996; Yao et al., 1999) and oviductal explants (Suarez et al., 1991) in vitro, results in functional changes in spermatozoa. Bound spermatozoa show extended viability (Ellington et al., 1993a) and delayed capacitation (Dobrinski et al., 1996b). The extended viability of spermatozoa bound to oviductal epithelial cells has also been observed in marsupials (Sidhu et al., 1998). The release of spermatozoa from oviductal epithelia is

*Correspondence

Email: ARFAZELI@ucl.ac.uk associated with a change to the capacitated state (Lefebvre and Suarez, 1996). Released spermatozoa show hyperactivated motility (Yanagimachi, 1994) and an increase in intracellular calcium concentration (Dobrinski et al., 1996b), ensuring that spermatozoa are in an appropriate condition for fertilization.

Despite elucidation of physiological changes in both spermatozoa and oviductal epithelial cells (Ellington et al., 1993b; Thomas et al., 1995) during binding, the molecular basis of interactions between spermatozoa and oviductal epithelia remains to be established. Studies in horses (Dobrinski et al., 1996a), hamsters (DeMott et al., 1995) and cattle (Lefebvre et al., 1997; Suarez et al., 1998) have demonstrated the presence of carbohydrate-mediated interactions between spermatozoa and oviductal epithelial cells in vitro. Interactions between spermatozoa and Sertoli cells (Raychoudhury and Millette, 1997), and spermatozoa and zona pellucida (Oehninger et al., 1991) involve carbohydrate recognition. Lectin-like interactions are important for adhesion between many types of cell and have been particularly well characterized in leucocytes, involving selectin cell adhesion molecules (Huang et al., 1997). To date, specific carbohydrate moieties involved in binding of boar spermatozoa to pig oviductal epithelial cells have not been determined. Therefore, in the present study the role of carbohydrates in the mediation of sperm-oviductal epithelial cell binding in pigs was investigated.

Other studies investigating mammalian sperm-oviductal epithelial cell interactions in vitro have used oviductal epithelial cells in the form of monolayers (Fazeli et al., 1999) and explants (Suarez et al., 1991). In the present 
study, the development and validation of a novel free cell bioassay for studying sperm-oviductal epithelial cell interactions in vitro was described.

\section{Materials and Methods}

\section{Preparation of spermatozoa}

Boar semen obtained from the Pig Improvement Company (PIC) UK was collected by manual methods, and then diluted and stored for $24 \mathrm{~h}$ in Beltsville thawing solution (BTS; $205 \mathrm{mmol}$ glucose $\mathrm{I}^{-1}, 20 \mathrm{mmol}$ sodium citrate dihydrate $\mathrm{I}^{-1}, 15 \mathrm{mmol} \mathrm{NaHCO}_{3} \mathrm{I}^{-1}, 4 \mathrm{mmol}$ EDTA $\left.\mathrm{I}^{-1}, 10 \mathrm{mmol} \mathrm{KCl} \mathrm{I}^{-1}, \mathrm{pH} 7.2\right)$. On the day of the experiments, diluted boar semen (30-40 ml) was washed by layering the semen over a two-step iso-osmotic Percoll (Sigma, Poole) gradient (Harrison et al., 1993). The isoosmotic Percoll gradient consisted of $2 \mathrm{ml} \mathrm{70 \%} \mathrm{(v/v)} \mathrm{Percoll}$ overlaid with $2 \mathrm{ml} \mathrm{35 \%}(\mathrm{v} / \mathrm{v})$ Percoll. The gradient was overlaid with $10 \mathrm{ml}$ diluted semen and centrifuged at $200 \mathrm{~g}$ for $5 \mathrm{~min}$, followed by $15 \mathrm{~min}$ at $900 \mathrm{~g}$. The supernatant was removed carefully and the sperm pellet was recovered from the bottom of the $70 \%(\mathrm{v} / \mathrm{v})$ Percoll gradient. The concentration of semen was measured in duplicate using a haemocytometer. Unless otherwise stated, the concentration of the washed semen sample was adjusted to $150 \times 10^{6}$ spermatozoa $\mathrm{ml}^{-1}$ with TCM-199 (Life Technologies, Paisley) supplemented with $10 \%$ fetal calf serum, 100 iu penicillin $\mathrm{ml}^{-1}, 100 \mu \mathrm{g}$ amphotericin B ml-1 and 0.25 g streptomycin $\mathrm{ml}^{-1}$ (Life Technologies) (M199).

\section{Preparation of oviductal epithelial cells}

Oviductal epithelial cells were prepared as described by Fazeli et al. (1999). Briefly, oviducts from prepubertal gilts of approximately 120 days of age, with ovaries that did not show signs of cyclicity, were obtained from a local abattoir. The oviducts were washed in PBS and separated from the ovaries and then transferred to a washing medium containing Hank's balanced salt solution (Life Technologies) supplemented with $100 \mathrm{iu}$ penicillin $\mathrm{ml}^{-1}, 100 \mu \mathrm{g}$ streptomyocin $\mathrm{ml}^{-1}$ and $0.25 \mu \mathrm{g}$ amphotericin $\mathrm{B} \mathrm{ml}-1$ for rinsing. Each oviduct was divided into three sections. One section, between the fimbria and the middle of the oviductal tube, containing the thicker part of the oviduct, was designated as the ampulla. A section containing 1-2 cm of the caudal part of the uterine horn, uterotubal junction and almost up to the middle of the oviduct containing the thinner part of the oviduct was designated as the isthmus. Finally, a section at the junction of the thin and thick part of the oviduct, approximately $1-2 \mathrm{~cm}$ long, was cut and discarded to ensure differentiation of isthmic and ampullar sections of the oviduct. Only the isthmic section of the oviduct was opened longitudinally. The epithelial cells were scraped using the blunt side of a scalpel blade. The media containing scraped tissues from the isthmus were collected and after initial sedimentation were centrifuged for $3 \mathrm{~min}$ at $100 \mathrm{~g}$. The supernatant was discarded and $5 \mathrm{ml}$ M199 was added to the pellet. The cells were mixed gently and were disaggregated by being passed once through a 21-gauge needle. The concentration of isthmic epithelial cells was measured using a haemocytometer. Cellular integrity was evaluated by mixing a sample of the cells with an equal volume of $4 \%(w / v)$ trypan blue (Sigma) dissolved in PBS. A tissue culture flask $\left(75 \mathrm{~cm}^{2}\right.$; Nalge Nunc International, Naperville, IL) was seeded with isthmic epithelial cells $\left(1 \times 10^{6}\right.$ viable cells $\left.\mathrm{ml}^{-1}\right)$. The flask was incubated at $39^{\circ} \mathrm{C}$ in an atmosphere of $100 \%$ humidity and $5 \% \mathrm{CO}_{2}$ in air. The culture medium was refreshed every $48-72 \mathrm{~h}$.

Isthmic epithelial cells reached confluence between day 7 and day 14. At confluency, cells were rinsed three times with PBS in the absence of $\mathrm{Ca}^{2+}$ and $\mathrm{Mg}^{2+}$ (Life Technologies), and were then detached by incubation with $3 \mathrm{ml}$ trypsin-EDTA solution (Life Technologies) containing $0.5 \mathrm{mg}$ trypsin $\mathrm{ml}^{-1}$ and $0.2 \mathrm{mg}$ EDTA $\mathrm{ml}^{-1}$ for $15 \mathrm{~min}$ at $39^{\circ} \mathrm{C}$. The concentration and viability of detached cells were measured before the cells were resuspended in fresh M199 supplemented with 10\% (v/v) glycerol (BDH, Poole). Aliquots of epithelial cell samples containing $1 \times 10^{6}$ viable cells $\mathrm{ml}^{-1}$ were divided into $1 \mathrm{ml}$ samples in cryogenic vials and stored at $-70^{\circ} \mathrm{C}$ overnight before transfer to liquid nitrogen.

A frozen cryogenic vial of isthmic epithelial cells was thawed at $37^{\circ} \mathrm{C}$ in a waterbath. M199 $(9 \mathrm{ml})$ was added to frozen-thawed cells, and the cell suspension was mixed gently. Cells were centrifuged at $200 \mathrm{~g}$ for $2 \mathrm{~min}$. The supernatant was discarded and a further $9 \mathrm{ml}$ of fresh M199 was added. The concentration of isthmic epithelial cells was adjusted to $5 \times 10^{4}$ viable cells $\mathrm{ml}^{-1}$. Oviductal epithelial cells were seeded in $75 \mathrm{~cm}^{2}$ flasks and cultured to confluency. The culture medium was refreshed every 48-72 h.

On the day of the experiments, cells were separated using trypsin as described above. Trypsinized cells were washed once with $10-15 \mathrm{ml} \mathrm{M199}$ by centrifugation at $200 \mathrm{~g}$ for $5 \mathrm{~min}$. The supernatant was discarded and the cells were resuspended in $1 \mathrm{ml}$ M199. The concentration of oviductal epithelial cells was measured and cell viability was assessed by Trypan blue exclusion as described previously. Unless otherwise stated, the concentration of the isthmic oviductal epithelial cell sample was adjusted to $2 \times 10^{6}$ oviductal epithelial cells $\mathrm{ml}^{-1}$. An aliquot of the detached isthmic cell suspension was sub-cultured for future experiments. Sub-cultures of isthmic cells were maintained as described above, for up to 1 week, before the cells were detached for experimental use. Successive subculturing was carried out after each experiment or at 1 week intervals.

\section{Co-incubation of sperm-oviductal epithelial cells}

Two hundred microlitres of the prepared semen sample was added to an equal volume of detached oviductal epithelial cells in an Eppendorf tube (Life Sciences). The sperm-oviductal epithelial cell suspension was mixed 
gently and incubated for $30 \mathrm{~min}$ on rotation at $39^{\circ} \mathrm{C}$, unless otherwise stated. After co-incubation, sperm-oviductal epithelial cell complexes were washed to remove unbound or loosely attached spermatozoa. The sperm-oviductal epithelial cell suspension $(400 \mu \mathrm{l})$ was layered over an isoosmotic two-step Percoll gradient. The gradient consisted of $1 \mathrm{ml} 70 \%$ (v/v) Percoll overlaid with $1 \mathrm{ml} 35 \%$ (v/v) Percoll. Sperm-oviductal epithelial cell complexes were centrifuged at $200 \mathrm{~g}$ for $2.5 \mathrm{~min}$. After centrifugation, three layers of cells were apparent. Non-motile, unbound spermatozoa and unattached oviductal epithelial cells were located primarily at the interface between the media and the $35 \%$ (v/v) Percoll layer (layer 1). Sperm-oviductal epithelial cell complexes were located predominantly at the interface between the $35 \%$ and $70 \%$ (v/v) Percoll layers (layer 2). Unattached, highly motile spermatozoa were sedimented at the bottom of the $70 \%(\mathrm{v} / \mathrm{v})$ Percoll gradient (layer 3). Motile unattached spermatozoa in layer 3 were discarded. Cells in layers 1 and 2, containing immotile unbound spermatozoa and unbound oviductal epithelial cells, and spermoviductal epithelial cell complexes, respectively, were removed carefully using a pipette. The cell suspensions were combined and diluted to a final volume of $15 \mathrm{ml}$ with PBS. The diluted cell suspension was washed by centrifugation at $200 \mathrm{~g}$ for $5 \mathrm{~min}$ to remove most of the remaining unattached spermatozoa. The supernatant was discarded and the pelleted sperm-oviductal epithelial cell complexes were recovered. A further $500 \mu \mathrm{l}$ of fresh PBS was added and sperm-oviductal epithelial cell complexes were fixed with $1 \%(\mathrm{w} / \mathrm{v})$ formaldehyde (final concentration in PBS). Ten microlitres of the fixed cell suspension was placed on a microscope slide and a coverslip was added. The number of spermatozoa bound to 100 oviductal epithelial cells was assessed by light microscopy.

\section{Scanning electron microscopy}

Oviductal epithelial cells in suspension and spermoviductal epithelial cell complexes in suspension were used in scanning electron microscopy studies. One volume of the cell suspension was added to ten volumes of $2.5 \%(\mathrm{w} / \mathrm{v})$ gluteraldehyde (TAAB Laboratories Limited, Aldermaston) in Sorenson's phosphate buffer. The fixative used was maintained at the same temperature as the samples $\left(23^{\circ} \mathrm{C}\right)$ before fixing to prevent any possible temperature shock or damage to the samples. Approximately $250 \mu$ of the cell suspension was placed on poly-L-lysine-coated (Sigma) coverslips for $10 \mathrm{~min}$. The coverslip was rinsed using Sorenson's phosphate buffer. All samples were post-fixed for $1 \mathrm{~h}$ in $1 \%(\mathrm{w} / \mathrm{v})$ osmium tetroxide (TAAB) in Sorenson's phosphate buffer, and then rinsed several times in buffer. Samples were dehydrated through an ascending series of ethanol (30, 50, 70 and 90\%) and with several changes in absolute ethanol. The samples were dried in a Samdri 780 critical point drier (Tousimis Research Corporation, MD). The coverslips were attached to aluminium stubs using sticky tabs (AGAR) and were coated with gold for $90 \mathrm{~s}$ using an SC500 coating unit (Emscope, Ashford). Finally, samples were examined and photographed using an S-450 scanning electron microscope (Hitachi Scientific Instruments, Reading).

\section{Validation for the bioassay}

Effect of sperm concentration on sperm-oviductal epithelial cell binding. The effect of sperm concentration on the binding of sperm-oviductal epithelial cells was examined. Washed semen samples $(n=4)$ were serially diluted with M199. Two hundred microlitres of diluted semen sample was added to an equal volume of oviductal epithelial cells. Final sperm concentrations of 1, 10, 50 and $100 \times 10^{6}$ spermatozoa $\mathrm{ml}^{-1}$ with $1 \times 10^{6}$ oviductal epithelial cells $\mathrm{ml}^{-1}$ were tested. Sperm-oviductal epithelial cell suspensions were incubated for $15 \mathrm{~min}$ on rotation at $39^{\circ} \mathrm{C}$. Thereafter, sperm-oviductal epithelial cell complexes were washed, fixed and the number of spermatozoa bound to 100 oviductal epithelial cells was counted as described previously.

Effect of duration of co-culture incubation on sperm-oviductal epithelial cell binding. Equal volumes of washed semen sample $(200 \mu \mathrm{l})$ and oviductal epithelial cells were combined and incubated on rotation at $39^{\circ} \mathrm{C}$ for $5,10,15,30$ or $60 \mathrm{~min}(n=3)$. Final concentrations of spermatozoa and oviductal epithelial cells were $50 \times 10^{6}$ spermatozoa $\mathrm{ml}^{-1}$ and $1 \times 10^{6}$ oviductal epithelial cells $\mathrm{ml}^{-1}$, respectively. After co-incubation, sperm-oviductal epithelial cell complexes were washed, fixed and the number of sperm bound to 100 oviductal epithelial cells was counted as described previously.

Effect of sperm membrane integrity (viability) on sperm-oviductal epithelial cell binding. Different proportions of spermatozoa with damaged membranes (dead) were co-incubated with oviductal epithelial cells to investigate the effect of sperm membrane integrity on sperm-oviductal epithelial cell binding $(n=4)$. An aliquot of the washed semen sample $\left(150 \times 10^{6}\right.$ spermatozoa $\left.\mathrm{ml}^{-1}\right)$ was subjected to repeated cycles of freezing and thawing to damage sperm membranes. One millilitre of washed semen sample in a $15 \mathrm{ml}$ poly-propylene tube (Nalge Nunc) was immersed in liquid nitrogen for approximately $1 \mathrm{~min}$ and was then thawed rapidly in a $39^{\circ} \mathrm{C}$ waterbath. This procedure was repeated five times. A dual fluorescent staining procedure, using carboxyfluorescin diacetateacetyomethoxyester (CFDA-AM) and ethidium homodimer1 (ETHD-1), was used to measure the integrity of the sperm membrane of frozen-thawed and washed semen samples by flow cytometry. Sub-samples of washed and frozenthawed semen were diluted to $2 \times 10^{6}$ spermatozoa $\mathrm{ml}^{-1}$ with M199. CFDA-AM (dissolved in DMSO) and ETHD-1 (dissolved in deionized water) were added at $50.0 \mathrm{ng} \mathrm{ml}^{-1}$ and $3.4 \mu \mathrm{g} \mathrm{ml}^{-1}$, respectively. Semen samples were incubated for $10 \mathrm{~min}$ at ambient temperatures and the percentages of live and dead spermatozoa were assessed using flow 
cytometry (Coulter EPICS XL; Coulter Electronics, Hialeah, $\mathrm{FL})$.

Various proportions of frozen-thawed semen samples containing approximately $94.5 \pm 1.6 \%$ ETHD-1 positive (dead) spermatozoa were combined with washed semen samples (16 $\pm 0.75 \%$ ETHD-1 positive). Combined semen samples consisted of $0,25,50,75$ or $100 \%$ frozen-thawed semen, with a total cell concentration of $150 \times 10^{6}$ spermatozoa $\mathrm{ml}^{-1}$. Two hundred microlitres of combined semen samples was co-incubated with equal volumes of oviductal epithelial cells for $30 \mathrm{~min}$ on rotation at $39^{\circ} \mathrm{C}$. Sperm-oviductal epithelial cell suspensions were washed, fixed and the number of spermatozoa bound to 100 oviductal epithelial cells was counted as described previously.

Sperm binding to a kidney epithelial cell line (LLCPK-1). Washed semen samples were incubated with a kidney epithelial cell line (LLCPK-1; European Collection of Animal Cell Cultures, Wiltshire) or with oviductal epithelial cells to investigate the specificity of sperm-epithelial cell interactions $(n=4)$. Frozen cryogenic vials of LLCPK- 1 were thawed, and the cells were washed and cultured to confluency, as described for oviductal epithelial cells.

On the day of the experiments, flasks of LLCPK-1 and oviductal epithelial cells were detached using trypsin. Cell samples were washed, the concentration and viability determined, and the concentration adjusted to $2 \times 10^{6}$ cells $\mathrm{ml}^{-1}$, as described previously. Two hundred microlitres of washed semen sample $\left(150 \times 10^{6}\right.$ spermatozoa $\left.\mathrm{ml}^{-1}\right)$ was added to an equal volume of LLCPK-1 or oviductal epithelial cell sample and incubated on rotation for $30 \mathrm{~min}$ at $39^{\circ} \mathrm{C}$. Sperm-epithelial cell suspensions were washed, and fixed, and the number of spermatozoa bound to 100 epithelial cells was counted.

\section{Carbohydrate inhibition studies}

Involvement of carbohydrate recognition in spermoviductal epithelial cell binding was investigated by incubation of sperm-oviductal epithelial cell suspensions in the presence of several monosaccharide and disaccharide hexose sugars. Carbohydrate monomers D-galactose, D-fucose, D-glucose and D-mannose, and dimers $\alpha$-lactose and $\alpha$-maltose (Sigma) were tested for their ability to inhibit binding of sperm-oviductal epithelial cells at various concentrations. Experiments were replicated using semen samples from four different boars (except mannose, $n=3$ ).

Spermatozoa $\left(300 \times 10^{6} \mathrm{ml}^{-1}\right)$ and oviductal epithelial cells $\left(4 \times 10^{6} \mathrm{ml}^{-1}\right)$ were pre-incubated separately in the presence of 50, 10, 2 and 0 (control) mmol $\mathrm{I}^{-1}$ of different carbohydrates for $15 \mathrm{~min}$ on rotation at $39^{\circ} \mathrm{C}$. Subsequently, $200 \mu \mathrm{l}$ of semen sample and an equal sample of oviductal epithelial cells, with the same sugar content and concentration, were mixed and incubated together for $30 \mathrm{~min}$. Sperm motility was examined at the end of the co-incubation period to ensure that carbohydrate treatments did not adversely affect sperm function. Sperm-oviductal epithelial cell complexes were washed, fixed and the number of spermatozoa bound to 100 oviductal epithelial cell was counted.

\section{Statistical analysis}

The data for the preliminary experiments were expressed as the mean number of spermatozoa bound per 100 oviductal cells \pm SEM. Data for carbohydrate inhibition experiments were expressed as a mean percentage of the control samples \pm SEM (sperm binding index). The Shapiro-Wilks test was used to confirm that data were distributed normally. ANOVA was used to examine the effect of treatments within the experimental designs. Results for the validation experiments were examined for the effect of sperm concentration, co-incubation period, integrity of sperm plasma membrane and epithelial cell origin. The effect of the type and concentration of carbohydrate was also examined. The level of significance was $P \leqslant 0.05$. Post hoc comparisons were made using least significant difference (LSD) calculations between sample treatments.

\section{Results}

\section{Sperm-oviductal epithelial cell co-incubation}

Epithelial cell monolayers cultured in $\mathrm{M} 199$ at $39^{\circ} \mathrm{C}$ in $5 \% \mathrm{CO}_{2}$ reached confluency between day 4 and day 7 . Proliferating monolayers exhibited typical epithelial features with well packed polygonal cells that did not overlap. In contrast, detached oviductal epithelial cells were spherical and ranged in diameter from 7.5 to $17.5 \mu \mathrm{m}$. There was no relationship between the size of the oviductal epithelial cells and the number of spermatozoa bound to each oviductal epithelial cell. Sperm binding was not distributed evenly between individual oviductal epithelial cells, ranging from 0 to 44 spermatozoa per oviductal epithelial cell, and there were differences among boars in the number of spermatozoa bound to oviductal epithelial cell (data not shown). Continued sub-culturing of oviductal epithelial cells resulted in a tendency towards reduced binding of sperm-oviductal epithelial cells. Spermatozoa were bound tightly to oviductal epithelial cells; binding was not disrupted even after centrifugation through the Percoll gradient.

\section{Scanning electron microscopy}

Individual oviductal epithelial cells varied in shape and size. Approximately 95\% of the cells were spherical and covered by microvilli (Fig. 1). However, nearly all cells had petal-like structures on part of the cell surface (Fig. 2). Approximately $2-5 \%$ of the oviductal epithelial cells had long villi and a distorted shape (Fig. 1). Scanning electron micrographs revealed that all spermatozoa bound to oviductal epithelial cells by the apical portion of the sperm head and all spermatozoa possessed intact acrosomes. Microvilli of oviductal epithelial cells were of various lengths, but this did not seem to affect the number of spermatozoa attached (Fig. 3a,b). 


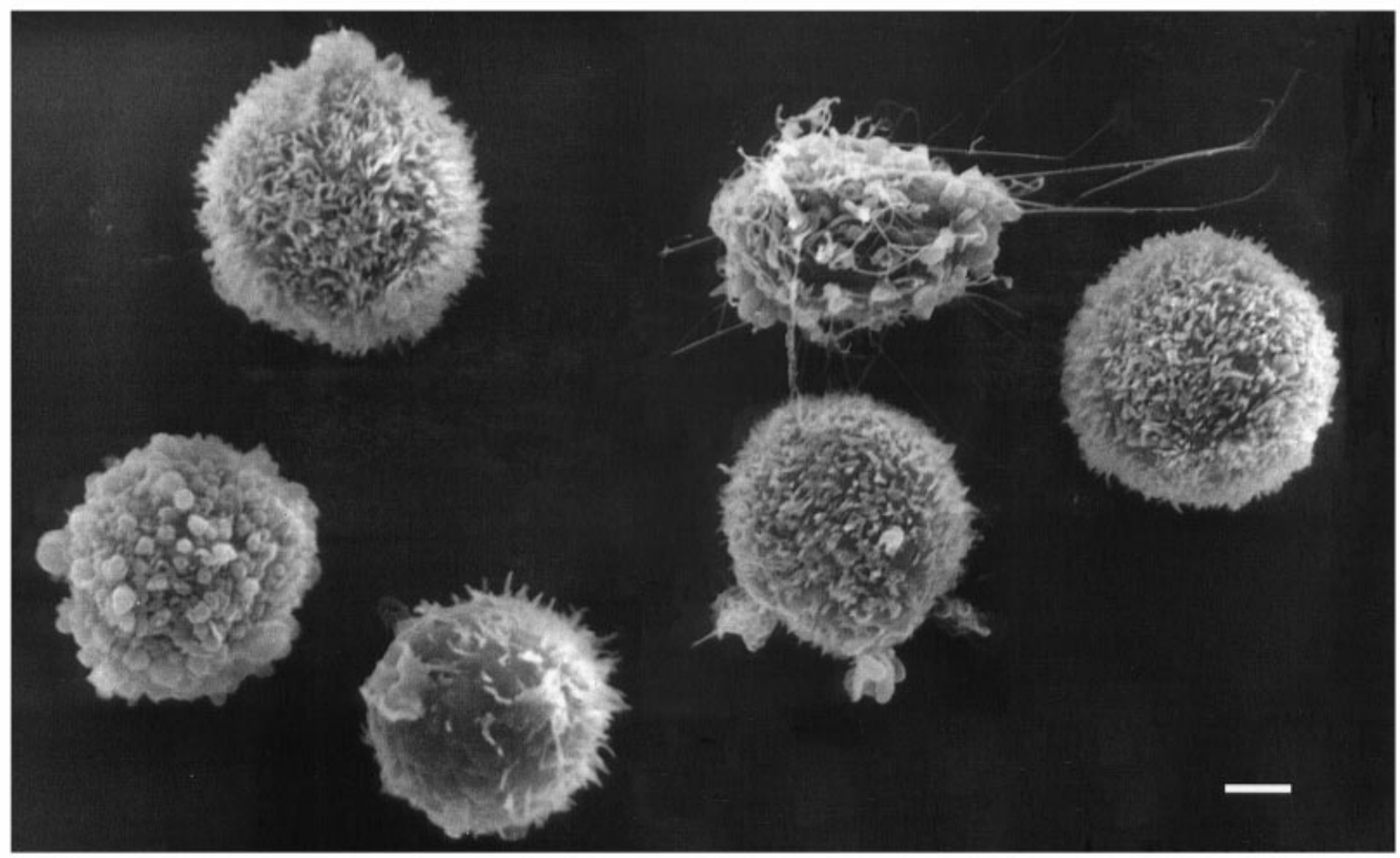

Fig. 1. Scanning electron micrograph of oviductal epithelial cells. Most of the cells are spherical with microvilli on their surface. Some oviductal epithelial cells $(2-5 \%)$ are irregularly shaped with cilia or long villi on their surfaces. Scale bar represents $2 \mu \mathrm{m}$.

\section{Effect of sperm concentration on sperm-oviductal epithelial cell binding}

Co-incubation of oviductal epithelial cells with various concentrations of spermatozoa for $15 \mathrm{~min}$ at $39^{\circ} \mathrm{C}$ resulted in a highly significant effect on the number of spermatozoa bound to oviductal epithelial cells $(P<0.0001)$ (Fig. 4).

\section{Effect of duration of sperm-oviductal epithelial cell co- culture incubation on sperm-oviductal epithelial cell binding}

The effect of the duration of incubation on the number of sperm bound to oviductal epithelial cells is shown (Fig. 5; $P<0.05$ ). Incubation of sperm-oviductal epithelial cell suspensions for 5 or $10 \mathrm{~min}$ at $39^{\circ} \mathrm{C}$ on rotation resulted in a limited number of spermatozoa bound to oviductal epithelial cells $(43 \pm 29.5$ and $71 \pm 31.0$, respectively). After 15 min of incubation, there was a significant increase in the number of bound spermatozoa (691 \pm 317 ; $P<0.05)$, followed by a gradual increase thereafter.

\section{Effect of sperm viability on spermatozoa to oviductal epithelial cells binding}

Loss of integrity of the sperm plasma membrane caused by repeated cycles of freezing and thawing significantly reduced the number of spermatozoa bound to oviductal epithelial cells $(P<0.005)$ (Fig. 6).

\section{Preferential binding of spermatozoa to oviductal epithelial cells or LLCPK-1}

Epithelial cells of the pig kidney (LLCPK-1) $(71 \pm 12.1)$ showed significantly lower sperm binding ability than oviductal epithelial cells $(574 \pm 12.1)$ incubated under identical conditions $(P<0.01)$.

\section{Carbohydrate inhibition studies}

The number of spermatozoa bound to oviductal epithelial cells significantly decreased when sperm-oviductal epithelial cell suspensions were incubated in the presence of 2 $(P<0.05), 10(P<0.05)$ and $50(P<0.0001)$ mmol maltose $\mathrm{I}^{-1}, 50 \mathrm{mmol}$ lactose $\mathrm{I}^{-1}(P<0.002)$ and $50 \mathrm{mmol}$ mannose $\mathrm{I}^{-1}$ $(P=0.05)$ (Fig. 7). Inhibition of the binding of sperm-oviductal epithelial cells was not detected in the presence of galactose, fucose or glucose (Fig. 7). There was a slight but significant $(P<0.05)$ increase in the number of spermatozoa bound to

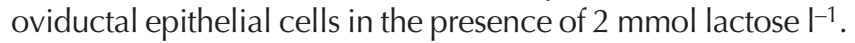
At the end of the co-incubation period, spermatozoa were highly motile even in the presence of the highest carbohydrate concentrations, indicating that the viability of spermatozoa had been retained. 


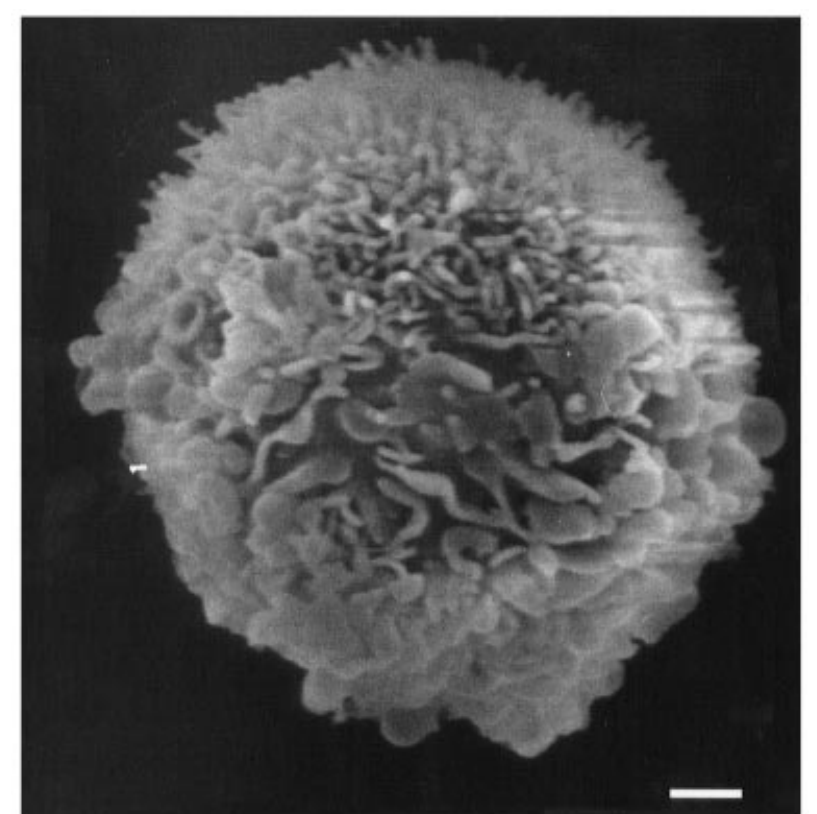

Fig. 2. Representative electron micrograph showing petal-like structures on most of the detached oviductal epithelial cells. Scale bar represents $1 \mu \mathrm{m}$.

\section{Discussion}

Current methods for investigating the mechanisms of sperm-oviductal epithelial cell interactions rely on the use of in vivo models (Suarez, 1987), oviductal explants (Suarez et al., 1991; DeMott et al., 1995) or oviductal epithelial cells in the form of monolayers (Dobrinski et al., 1996b; Sidhu et al., 1998; Fazeli et al., 1999). The use of live animals as an experimental model does not provide a viable option for analysis of the binding of sperm-oviductal epithelial cells in pigs. Unlike species such as hamsters and mice, pigs do not have transparent oviducts that allow detection of sperm transport and oviductal interactions in vivo. Furthermore, the use of live animals for experimentation is costly and invites ethical considerations.

Although oviductal explants provide a system for monitoring sperm binding directly to fresh oviductal tissue in vitro, this method poses problems of practicality and accuracy. For continuous experiments, the use of explants is time consuming and expensive, as the explants must be obtained regularly from abattoir material. Binding of spermatozoa to oviductal explants is often difficult to assess by microscopy and only permits assessment of spermatozoa attached to cells located at the edge of the explant.

Similarly, detection of sperm binding to oviductal epithelial cell monolayers is often difficult. Sperm binding is not homogeneous across the monolayers, resulting in irregular attachments to oviductal epithelial cells. Although this irregular attachment is a characteristic of oviductal epithelial cells both in vivo (Hunter, 1981; Hunter and Nichol, 1983; Smith and Yanagimachi, 1990) and in vitro (Gualtieri and Talevi, 2000), it necessitates monitoring of large numbers of spermatozoa over binding and nonbinding areas. However, monolayers as an experimental model are advantageous in that they provide a ready source of oviductal material that is produced by in vitro culture. In addition, as an adherent sheet of cells, binding of spermatozoa to oviductal monolayers can be assessed by direct (Raychoudhury and Suarez, 1991; Gualtieri and Talevi, 2000) or indirect counting methods (by subtracting the number of spermatozoa recovered after co-culture) (Thomas et al., 1994; Chian and Sirard, 1995).

The use of oviductal epithelial cells in a free cell suspension has many advantages as an experimental system. Essentially, this system maintains the advantages of using oviductal epithelial cell monolayers, whereby an immediate source of cellular material is available through cell culture. Oviductal epithelial cells detached from the monolayer are spherical and, therefore, provide greater surface area for sperm attachment. The incubation of spermatozoa and oviductal epithelial cells on rotation also increases the likelihood of the cells coming into contact with each other, and ensures that the detached oviductal epithelial cells do not adhere to the tubes, which would prevent full recovery of cells. Indeed, the use of a free cell suspension permits simultaneous evaluation of oviductal epithelial cells that have not bound spermatozoa and oviductal epithelial cells bound to spermatozoa, by assessment of a random sub-sample of the total population.

Incubation of spermatozoa with oviductal epithelial cells resulted in a large variation in the number of spermatozoa bound per oviductal cell (0-44). A number of factors were shown to influence the formation of sperm-oviductal epithelial cell complexes. Both oviductal epithelial cells and variation in sperm sample affected the number of sperm-oviductal epithelial cell attachments. Variation within and between oviductal epithelial cell sub-culture samples was apparent. The effect of sperm binding to oviductal epithelial cells from successively sub-cultured monolayers was monitored throughout the experiment. A subset of results, in which spermatozoa and oviductal epithelial cells were incubated under identical control conditions, was used to show that repeated passages resulted in a tendency towards reduced sperm binding. This finding may be attributable to a decrease in the number of epithelial cells within the sample, which occurs in continually sub-cultured epithelial cells in vitro (Akhondi et al., 1997). In the present study, the oviductal epithelial cells were obtained by scraping the isthmic region of the oviduct. The isthmic region of the oviduct was defined as the caudal region of the uterine horn, uterotubal junction and the proximal part of the oviduct. The oviduct epithelium in these regions consists mainly of ciliated and secretory cells (Abe, 1996). The observed variation in the number of spermatozoa bound to oviductal epithelial cells may have been caused by heterogeneity of the types of cell used in the present investigation. The cellular anatomy of the oviductal epithelial cells may also play a role in mediation of sperm binding. Scanning electron micrographs of detached 

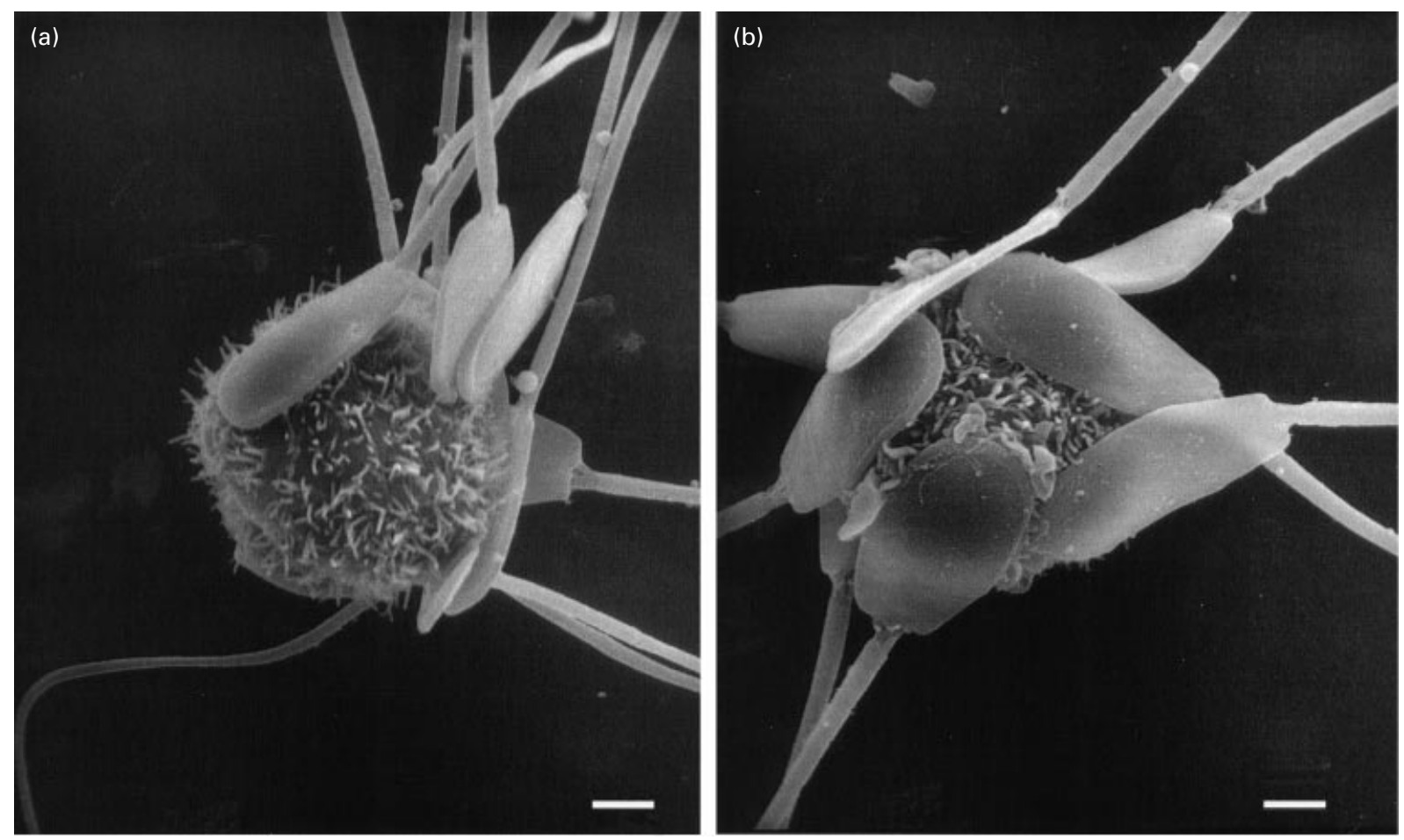

Fig. 3. (a,b) Scanning electron micrographs of spermatozoa bound to oviductal epithelial cells. Scale bars represent $2 \mu \mathrm{m}$.

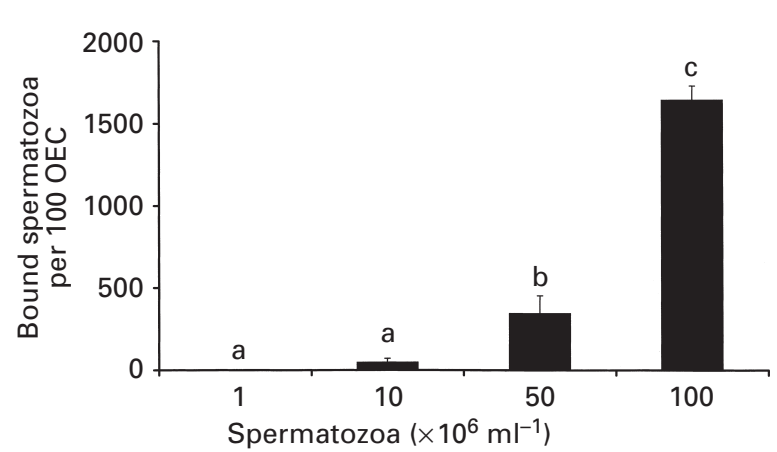

Fig. 4. The effect of sperm concentration on binding of boar spermatozoa to oviductal epithelial cells (OEC) $(n=3)$. abc Different letters denote significant differences between sperm concentrations $(P<0.0001)$.

oviductal epithelial cells showed a heterogeneity among cells within a sample, showing variation in the lengths of surface microvilli. Furthermore, the covering of microvilli on many individual cells was not uniform over the entire cell surface. Petal-like structures and often distended portions of the cells were apparent, indicating that detached oviductal epithelial cells maintain some form of polarity. It is possible that these folding structures may represent the point of attachment (basal membrane) to the flask during culture. As spermatozoa often covered a large proportion of the oviductal epithelial cell surface, it was difficult to assess

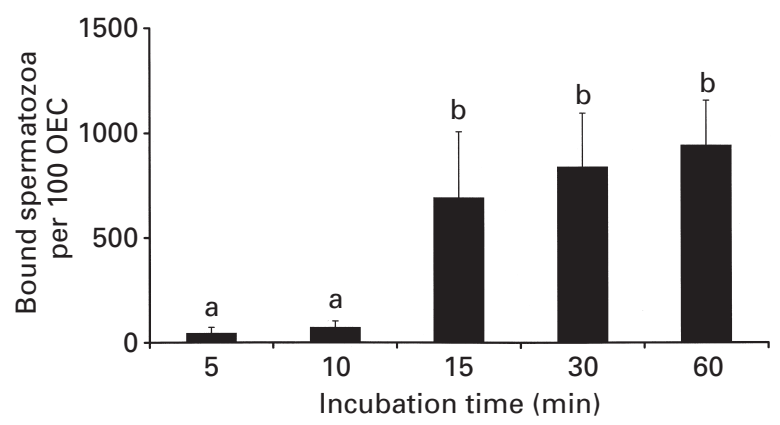

Fig. 5. The effect of duration of incubation on the number of spermatozoa bound to oviductal epithelial cells (OEC) $(n=4)$. ${ }^{a b}$ Different letters denote significant differences between time intervals $(P<0.05)$.

whether differences in the structure of the oviductal epithelial cell surface affected their binding ability. In addition to variability among normal boar spermatozoa, visible pathologies, for example high incidence of sperm tails with hairpin loops, were shown to reduce the overall number of spermatozoa bound to oviductal epithelial cells (data not shown). Furthermore, scanning electron micrographs demonstrated that a sub-population of sperm cells was preferentially binding to oviductal epithelial cells, that is, those that were acrosome intact. This finding supports the observation of Gualtieri and Talevi (2000) that only acrosome intact spermatozoa bind to oviductal epithelial cells in vitro. In many species, binding of sperm-oviductal 


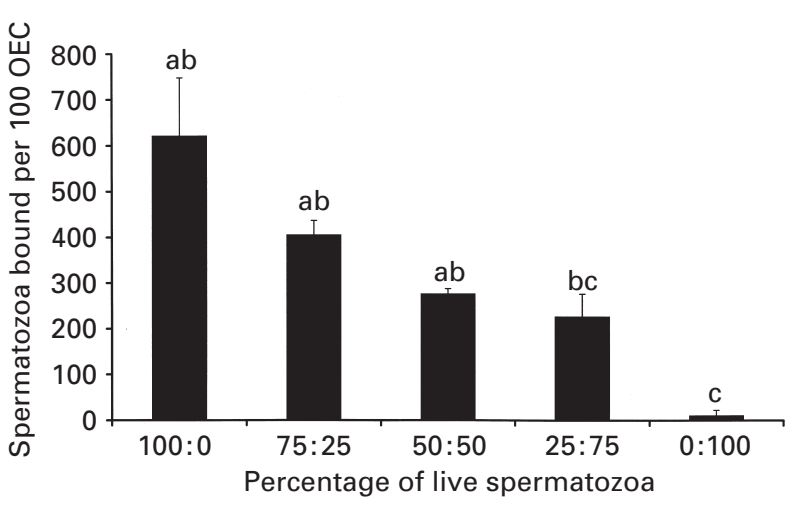

Fig. 6. The effect of rapid semen freezing and thawing (sperm membrane damage) on the number of spermatozoa bound to oviductal epithelial cells (OEC) $(n=4)$. abcDifferent letters denote significant differences between treatments $(P<0.005)$.

epithelial cells has revealed selectivity for functional and intact spermatozoa within a sample. Indeed, the specificity of sperm-oviductal epithelial cell interactions is such that even spermatozoa that have undergone capacitation (Lefebvre and Suarez, 1996; Fazeli et al., 1999) or show increases in intracellular calcium concentrations (Dobrinski et al., 1996b) are less able to interact with oviductal epithelial cells. As such, measurement of sperm-oviductal epithelial cell interactions may provide a useful tool for assessing fertility in individual boars.

In a free cell system, trypsin used to separate oviductal epithelial cells may influence cell surface characteristics. However, Cottrill et al. (1986) showed that cell partitioning procedures based on surface properties can still be performed on trypsinized cells, implying that trypsin digestion can be used to obtain a cell suspension without altering the surface components of the cells. A series of preliminary experiments were performed to validate this technique of measuring sperm-oviductal epithelial cell binding to ensure that the use of trypsin did not compromise the ability of oviductal epithelial cells specifically to bind spermatozoa. Results from these experiments determined the kinetics of sperm binding to oviductal epithelial cells and highlighted the effects of sperm plasma membrane damage and epithelial cell origin. In the first experiment of the present study, the number of spermatozoa bound to oviductal epithelial cells increased with increasing sperm concentrations, a result similar to that obtained for bovine sperm binding to oviductal monolayers (Gualtieri and Talevi, 2000). A similar response to Expt 1 was obtained in Expt 2 when measuring the effect of sperm-oviductal epithelial cell co-incubation period. However, there appeared to be a co-incubation time threshold $(15 \mathrm{~min})$ for the detection of numerous sperm-oviductal epithelial cell attachments. Incubation of spermatozoa and oviductal epithelial cells for periods $<15$ min resulted in minimal binding of spermoviductal epithelial cells, whereas only small increases in binding were detected after periods $>15 \mathrm{~min}$. From these results, optimized conditions for further experiments were established as $75 \times 10^{6}$ spermatozoa ml-1 with $1 \times 10^{6}$ oviductal epithelial cells $\mathrm{ml}^{-1}$ for $30 \mathrm{~min}$ on rotation at $39^{\circ} \mathrm{C}$. These parameters enabled detection of sufficient sperm-oviductal epithelial cell binding without posing problems of counting accuracy or reaching saturation point of the assay. The number of spermatozoa bound after 30 min of co-incubation was directly related to the proportion of frozen-thawed spermatozoa within the sample. Expt 3 highlighted the requirement for functional, membraneintact spermatozoa for the tight binding of spermatozoa and oviductal epithelial cells. These data are consistent with the findings of Ellington (1993a) in which heat-killed spermatozoa failed to bind to oviductal epithelial cell monolayers. In Expt 4, specificity of sperm binding to oviductal epithelial cells was also established in the live sperm population. The total number of spermatozoa bound to oviductal epithelial cells was more than eight times that of spermatozoa bound to LLCPK-1, when incubated under comparable conditions. These results indicate that incubation of spermatozoa and oviductal epithelial cells in a free cell system provides a rapid and sensitive method for determination of spermoviductal epithelial cell interactions.

The mediation of carbohydrate recognition during sperm-oviductal epithelial cell binding appears to be species-specific. In all species studied to date, different carbohydrates have provided the most effective inhibition of sperm-oviductal epithelial cell binding. In cattle, fucose and the glycoprotein fucoidin are potent inhibitors of sperm binding to oviductal explants (Lefebvre et al., 1997). In horses (Dobrinski et al., 1996a) and hamsters (DeMott et al., 1995), galactose and sialic acid, respectively, inhibit sperm binding to oviductal epithelial cell monolayers. In the present study, the disaccharides lactose and maltose, and the monosaccharide mannose were effective inhibitors of boar sperm binding to oviductal epithelial cells. It would therefore appear that different carbohydrate mediators of sperm-oviductal epithelial cell binding have evolved in different species. This is not surprising considering that the specificity of some protein binding domains (selectins) for a given carbohydrate can be altered by the change of a single amino acid (Kogan et al., 1995; Revelle et al., 1996).

Whether sperm-oviductal epithelial cell interactions are mediated by carbohydrate-binding proteins on the membrane of spermatozoa or the oviductal plasma membrane has yet to be confirmed. However, evidence from other studies indicates the involvement of glycoproteins on the oviductal epithelial cell surface in conjunction with sperm plasma membrane carbohydrate recognition domains. Adherence of Lewis-a trisaccharide to acrosome intact bull spermatozoa (Suarez et al., 1998) and fetuin to hamster spermatozoa (DeMott et al., 1995) interfered with spermoviductal epithelial cell binding. In support of this finding, enzymatic removal of fucose residues from bovine oviductal epithelia resulted in a marked reduction in sperm binding (Lefebvre et al., 1997). However, interpretation of such results should be approached cautiously, as commercially available glycosidases contain traces of proteases and other 
(a)
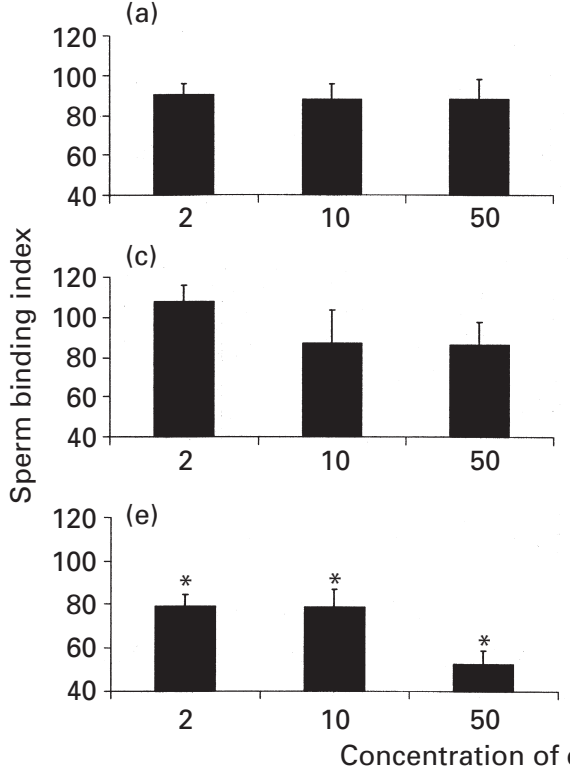

(b)
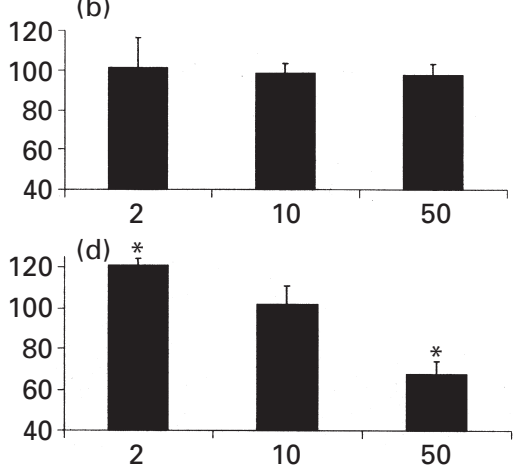

(f)

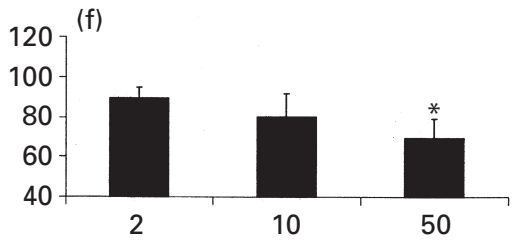

Fig. 7. Percentage index of spermatozoa bound to oviductal epithelial cells (OEC) in the presence of (a) fucose, (b) galactose, (c) glucose, (d) lactose, (e) maltose and (f) mannose at concentrations of 2, 10 and $50 \mathrm{mmol} \mathrm{I}^{-1}$ of each sugar compared with media only $\left(0 \mathrm{mmol} \mathrm{I}^{-1}\right)$ samples. Experiments were performed using semen samples from four different boars (except for mannose; $n=3$ ). Within each carbohydrate, asterisks represent significantly different values compared with controls $(P \leqslant 0.05)$.

glycosidases. Removal of a specific type of sugar from a complex cell-surface glycocalyx is not possible (Varki, 1992).

Of the six carbohydrates tested for inhibition of pig sperm-oviductal epithelial cell binding, incubation with two disaccharides, lactose and maltose, and one monosaccharide (mannose) resulted in a reduced number of interactions. The effective inhibition of sperm-oviductal epithelial cell binding by larger carbohydrate molecules has been demonstrated in other species. In cattle (Lefebvre et al., 1997; Suarez et al., 1998), hamsters (DeMott et al., 1995) and horses (Dobrinski et al., 1996a), glycoproteins inhibit binding more effectively than their monosaccharide subunits. Ahuja (1985) suggested that these differences may be due to a decreased binding affinity of monosaccharides in comparison to oligosaccharides. The interaction between single sugar residues and protein carbohydrate binding domains is weak, occurring through a limited number of contacts between the ligand and receptor molecules (Weis et al., 1992b). Multiple interactions between individual monosaccharides within an oligosaccharide give rise to a spectrum of possible interactions (Varki, 1992; Weis et al., 1992b). Evidence from c-type lectin (calcium dependentcarbohydrate mediated) interactions indicate that high binding affinity of oligosaccharides may be due to a second saccharide binding site in the carbohydrate recognition domain. Alternatively, clustering of carbohydrate recognition domains at one site may permit multiple attachments to a single saccharide residue (Weis et al., 1992b). One of the most studied groups of c-type lectin cell adhesion molecules is the selectins. Selectins, known to have a low affinity for monosaccharides and specific binding to larger oligosaccahrides (Weis and Drickamer, 1996), are well characterized for their role in mediation of temporary interactions between leucocytes and platelets during inflammatory or infectious responses.

Recently, c-type lectins have been located on the plasma membranes of rat (Goluboff et al., 1995; Mertz et al., 1995) and human spermatozoa (Goluboff et al., 1995). Expression of P-selectin has been detected on acrosomal membranes of boar spermatozoa (Geng et al., 1997) and P-selectin glycoprotein ligand-1 (PSGL-1), which is primarily located on a subset of myeloid and lymphoid cells, has also been detected on epithelial cells of the Fallopian tube in humans (Laszik et al., 1996). Indeed, binding of bull spermatozoa to oviductal epithelial cell monolayers is inhibited by Lewis-a trisaccharide (Suarez et al., 1998), a carbohydrate with high homology to sialyl-Lewis X that is part of the CD15 antigen recognized by selectin molecules (Fusi et al., 1996), providing further evidence for a possible function of selectins in sperm-oviductal epithelial cell interactions.

Although oligosaccharide specificity of selectin molecules may provide a mechanism for lactose and maltose mediation of sperm-oviductal epithelial cell binding in pigs, it does not account for the reduced binding detected in the presence of the monosaccharide, mannose. Mannose binding sites and $\alpha$-D-mannosidase are prevalent on the sperm surface of many mammalian species (Mori et al., 1989; Tulsiani et al., 1990; Cornwall et al., 1991; Tesarik et al., 1991), and may play a role in pig sperm-oviductal epithelial cell interactions; however, to date they have only 
been implicated in sperm-oocyte binding. Alternatively, these findings may be explained by interactions of mannose with another group of specific c-type lectins: the mannosebinding proteins. Mannose-binding proteins, generally associated with the immune system in binding mannose residues of bacteria and fungi (Weis et al., 1992a), have similar fundamental features of selectins. If mannosebinding proteins are present on boar sperm plasma membranes, they could account for the specificity of mannose in inhibiting sperm-oviductal epithelial cell binding in pigs. However, mannose-binding proteins are not entirely specific for mannose ligands, and also recognize D-glucose and L-fucose (Weis et al., 1992a) with the same hydroxyl group positioning as mannose. As Dglucose and D-fucose monomers were unable to inhibit binding of sperm-oviductal epithelial cells in the same manner as mannose, it is likely that mediation of binding by mannose is through an as yet unknown specific receptor.

A further characteristic of carbohydrate interactions with c-type lectins and selectin molecules may also explain why several different carbohydrates were able to inhibit binding of pig spermatozoa to oviductal epithelial cells. Apparently unrelated carbohydrates are able to inhibit the same lectinlike interactions because of some aspects of their structure in free solution (Varki, 1992). Very few amino acids within the c-type carbohydrate recognition domains are actually involved in carbohydrate binding. As such, selectins are able to adhere to diverse monosaccharides by binding to homologous sites conserved within the carbohydrate molecules. The overall degree of sequence relatedness of c-type carbohydrate recognition domains is therefore not reflective of the saccharide binding characteristic (Weis et al., 1992b).

In conclusion, results from the present study have shown that a free cell co-culture technique can be used to investigate the mechanisms of sperm-oviductal epithelial cell binding in vitro in pigs. At present, this bioassay is new and its use is limited to small experimental designs due to the time taken for individual counts by light microscopy. An automated method for detecting sperm binding would add value to this technique. Use of this free cell co-incubation technique in the present study indicates that binding of pig spermatozoa to oviductal epithelial cells can be inhibited by a number of different carbohydrates. Considering the recent evidence, a possible model for mammalian spermoviductal epithelial cell interactions may involve selectin and c-type lectin interactions. Findings from the present study that demonstrate the preferential inhibition of binding by disaccharide sugars corroborate this contention. Characterization and isolation of the proteins involved in carbohydrate recognition are required to elucidate further the specificity and mechanisms of pig sperm-oviductal epithelial cell interactions, and their role in the formation of the isthmic sperm reservoir. Use of selectin-specific antibodies or recombinant P-selectin proteins are likely to be useful tools and techniques with which to test the specificity of receptors involved in sperm-oviductal epithelial cell binding.
The authors thank A. G. Hartley and R. Foot for their technical assistance, Dawkins abattoir for donation of pig oviductal tissue and the Pig Improvement Company (PIC, UK) for donation of boar semen samples. This study was supported by a grant from the Ministry of Agriculture, Fisheries and Food (UK). C. E. Green was supported partially by a grant from the PIC, UK.

\section{References}

Abe H (1996) The mammalian oviductal epithelium: regional variations in cytological and functional aspects of the oviductal secretory cells Histology and Histopathology 11 743-768

Ahuja KK (1985) Carbohydrate determinants involved in mammalian fertilization American Journal of Anatomy 174 207-223

Akhondi MA, Chapple C and Moore HD (1997) Prolonged survival of human spermatozoa when co-incubated with epididymal cell cultures Human Reproduction 12 514-522

Chian RC and Sirard MA (1995) Fertilizing ability of bovine spermatozoa cocultured with oviduct epithelial-cells Biology of Reproduction 52 156-162

Cornwall GA, Tulsiani DR and Orgebin-Crist MC (1991) Inhibition of the mouse sperm surface alpha-D-mannosidase inhibits sperm-egg binding in vitro. Biology of Reproduction 44 913-921

Cottrill CP, Sharpe PT and Wolpert L (1986) The application of aqueous two-phase partition to the study of chick limb mesenchymal diversification Journal of Embryology and Experimental Morphology 94 267-275

DeMott RP, Lefebvre R and Suarez SS (1995) Carbohydrates mediate the adherence of hamster sperm to oviductal epithelium Biology of Reproduction 52 1395-1403

Dobrinski I, Ignotz GG, Thomas PG and Ball BA (1996a) Role of carbohydrates in the attachment of equine spermatozoa to uterine tubal (oviductal) epithelial cells in vitro. American Journal of Veterinary Research 57 1635-1639

Dobrinski I, Suarez SS and Ball BA (1996b) Intracellular calcium concentration in equine spermatozoa attached to oviductal epithelial cells in vitro. Biology of Reproduction 54 783-788

Ellington JE, Ignotz GG, Varner DD, Marcucio RS, Mathison P and Ball BA (1993a) In vitro interaction between oviduct epithelial and equine sperm Archives of Andrology 31 79-86

Ellington JE, Varner DD, Burghardt RC, Meyerswallen VN, Barhoumi R, Brinsko SP and Ball BA (1993b) Cell-to-cell communication of equine uterine tube (oviduct) cells as determined by anchored cell analysis in culture Animal Reproduction Science 30 313-324

Fazeli A, Duncan AE, Watson PF and Holt WV (1999) Sperm-oviduct interaction: induction of capacitation and preferential binding of uncapacitated spermatozoa to oviductal epithelial cells in porcine species Biology of Reproduction 60 879-886

Fusi FM, Montesano M, Bernocchi N, Panzeri C, Ferrara F, Villa A and Bronson RA (1996) P-selectin is expressed on the oolemma of human and hamster oocytes following sperm adhesion and is also detected on the equatorial region of acrosome-reacted human spermatozoa Molecular Human Reproduction 2 341-347

Geng JG, Raub TJ, Baker CA, Sawada GA, Ma L and Elhammer AP (1997) Expression of a P-selectin ligand in zona pellucida of porcine oocytes and P-selectin on acrosomal membrane of porcine sperm cells. Potential implications for their involvement in sperm-egg interactions Journal of Cell Biology 137 743-754

Goluboff ET, Mertz JR, Tres LL and Kierszenbaum AL (1995) Galactosyl receptor in human testis and sperm is antigenically related to the minor C-type ( $\mathrm{Ca}^{2+}$-dependent) lectin variant of human and rat liver Molecular Reproduction and Development 40 460-466

Gualtieri R and Talevi R (2000) In vitro cultured bovine oviductal cells bind acrosome-intact sperm and retain this ability upon sperm release Biology of Reproduction 62 1754-1762

Harrison RA, Mairet B and Miller NG (1993) Flow cytometric studies of bicarbonate-mediated $\mathrm{Ca}^{2+}$ influx in boar sperm populations Molecular Reproduction and Development 35 197-208 
Huang K, Graves BJ and Wolitzky BA (1997) Functional analysis of selectin structure. In The Selectins: Initiators of Leukocyte Endothelial Adhesion 1st Edn pp 1-30 Ed. D Vestweber. Harwood Academic Publishers, Amsterdam

Hunter RH (1981) Sperm transport and reservoirs in the pig oviduct in relation to the time of ovulation Journal of Reproduction and Fertility $\mathbf{6 3}$ 109-117

Hunter RHF (1984) Pre-ovulatory arrest and peri-ovulatory redistribution of competent spermatozoa in the isthmus of the pig oviduct Journal of Reproduction and Fertility 72 203-211

Hunter RH and Nichol R (1983) Transport of spermatozoa in the sheep oviduct: preovulatory sequestering of cells in the caudal isthmus Journal of Experimental Zoology 228 121-128

Kogan TP, Revelle BM, Tapp S, Scott D and Beck PJ (1995) A single amino acid residue can determine the ligand specificity of E-selectin Journal of Biological Chemistry 27014 047-14 055

Laszik Z, Jansen PJ, Cummings RD, Tedder TF, McEver RP and Moore KL (1996) P-selectin glycoprotein ligand-1 is broadly expressed in cells of myeloid, lymphoid and dendritic lineage, and in some nonhematopoietic cells Blood $\mathbf{8 8} 3010-3021$

Lefebvre R and Suarez SS (1996) Effect of capacitation on bull sperm binding to homologous oviductal epithelium Biology of Reproduction 54 575-582

Lefebvre R, Lo MC and Suarez SS (1997) Bovine sperm binding to oviductal epithelium involves fucose recognition Biology of Reproduction $\mathbf{5 6}$ 1198-1204

Mertz JR, Banda PW and Kierszenbaum AL (1995) Rat sperm galactosyl receptor: purification and identification by polyclonal antibodies raised against multiple antigen peptides Molecular Reproduction and Development 41 374-383

Mori K, Daitoh T, Irahara M, Kamada M and Aono T (1989) Significance of D-mannose as a sperm receptor site on the zona pellucida in human fertilization American Journal of Obstetrics and Gynecology 161 207-211

Neubaum DM and Wolfner MF (1999) Wise, winsome or weird? Mechanisms of sperm storage in female animals Current Topics in Developmental Biology 41 67-97

Oehninger S, Clark GF, Acosta AA and Hodgen GD (1991) Nature of the inhibitory effect of complex saccharide moieties on the tight binding of human spermatozoa to the human zona pellucida Fertility and Sterility 55 165-169

Raychoudhury SS and Millette CF (1997) Multiple fucosyltransferases and their carbohydrate ligands are involved in spermatogenic cell-Sertoli cell adhesion in vitro in rats Biology of Reproduction 56 1268-1273

Raychoudhury SS and Suarez SS (1991) Porcine sperm binding to oviductal explants in culture Theriogenology 36 1059-1070

Revelle BM, Scott D and Beck PJ (1996) Single amino acid residues in the Eand P-selectin epidermal growth factor domains can determine carbohydrate binding specificity Journal of Biological Chemistry 27116 160-16 170

Sidhu KS, Mate KE and Rodger JC (1998) Sperm-oviduct epithelial cell monolayer co-culture: an in vitro model of sperm-female tract interactions in a marsupial, the tammar wallaby (Macropus eugenii) Journal of Reproduction and Fertility 114 55-61

Smith TT and Yanagimachi R (1990) The viability of hamster spermatozoa stored in the isthmus of the oviduct: the importance of sperm-epithelium contact for sperm survival Biology of Reproduction 42 450-457

Smith TT and Yanagimachi R (1991) Attachment and release of spermatozoa from the caudal isthmus of the hamster oviduct Journal of Reproduction and Fertility 91 567-573

Suarez SS (1987) Sperm transport and motility in the mouse oviduct: observations in situ. Biology of Reproduction 36 203-210

Suarez S, Redfern K, Raynor P, Martin F and Phillips DM (1991) Attachment of boar sperm to mucosal explants of oviduct in vitro: possible role in formation of a sperm reservoir Biology of Reproduction 44 998-1004

Suarez SS, Revah I, Lo M and Kolle S (1998) Bull sperm binding to oviductal epithelium is mediated by a $\mathrm{Ca}^{2+}$ dependent lectin on sperm that recognizes Lewis-a trisaccharide Biology of Reproduction 59 39-44

Tesarik J, Mendoza C and Carreras A (1991) Expression of D-mannose binding sites on human spermatozoa: comparison of fertile donors and infertile patients Fertility and Sterility 56 113-118

Thomas PG and Ball BA (1996) Cytofluorescent assay to quantify adhesion of equine spermatozoa to oviduct epithelial cells in vitro. Molecular Reproduction and Development 43 55-61

Thomas PG, Ball BA, Miller PG, Brinsko SP and Southwood L (1994) A subpopulation of morphologically normal motile spermatozoa attach to equine oviductal epithelial cell monolayers Biology of Reproduction $\mathbf{5 1}$ 303-309

Thomas PGA, Ignotz GG, Ball BA, Brinsko SP and Currie WB (1995) Effect of coculture with stallion spermatozoa on de novo protein synthesis and secretion by equine oviduct epithelial cells American Journal of Veterinary Research $\mathbf{5 6} 1657-1662$

Tulsiani DR, Skudlarek MD and Orgebin-Crist MC (1990) Human sperm plasma membranes possess alpha-D-mannosidase activity but no galactosyltransferase activity Biology of Reproduction 42 843-858

Varki A (1992) Selectins and other mammalian sialic acid-binding lectins Current Opinion in Cell Biology 4 257-266

Weis WI and Drickamer K (1996) Structural basis of lectin-carbohydrate recognition Annual Review of Biochemistry 65 441-473

Weis WI, Drickamer K and Hendrickson WA (1992a) Structure of a C-type mannose-binding protein complexed with an oligosaccharide Nature $360127-134$

Weis WI, Queensberry AM, Taylor ME, Bezouska K, Hendrickson WA and Drickamer K (1992b) Molecular mechanisms of complex carbohydrate recognition at the cell surface. In Cold Spring Harbour Symposia on Quantitative Biology pp 281-289. Laboratory Press, Cold Spring Harbour

Yanagimachi R (1994) Mammalian Fertilization. In The Physiology of Reproduction 2nd Edn pp 189-317 Eds E Knobil and JD Neil. Raven Press, New York

Yao YQ, Ho PC and Yeung WS (1999) Effects of human oviductal cell coculture on various functional parameters of human spermatozoa Fertility and Sterility 71 232-239

Received 17 January 2001.

First decision 9 March 2001

Accepted 19 April 2001. 